\title{
Peran Digital Marketing Terhadap Minat Berkunjung Wisatawan dalam Meningkatkan Pertumbuhan Ekonomi Kabupaten Garut : Store Atmosfer Variabel Moderating
}

\author{
Hani Siti Hanifah \\ Jurnal Algoritma \\ Universitas Garut \\ Jalan Raya Samarang No. 52. A, Tarogong Kidul, Garut 44151 Indonesia \\ Email : rektorat@uniga.ac.id \\ hanisiti1965@uniga.ac.id
}

\begin{abstract}
Abstrak - Pemulihan ekonomi nasional dan pertumbuhan ekonomi pasca pandemi Covid-19 dengan mengembangkan sektor prioritas seperti pada sektor pariwisata. Potensi daya tarik wisata yang dimiliki kota Garut, antara lain berupa keanekaragaman hayati, keunikan dan keaslian budaya daerah, keindahan bentang alam dan peninggalan sejarah sebagai salah satu bidikan penerimaan daerah yang berkontribusi pada kesejahteraan masyarakat. Tujuan penelitian untuk mengetahui peran digital marketing terhadap minat berkunjung wisatawan dalam meningkatkan pertumbuhan ekonomi kabupaten garut dan store atmosphere sebagai variabel moderating. Penelitian ini dengan menggunakan metode studi kasus mensyaratkan sumber data yang multi sources. Hasil penelitian menunjukkan bahwa upaya mendorong laju sektor pariwisata salah satunya dengan digital marketing dan tetap memperhatikan aspek store atmosphere sehingga dapat mendorong minat berkunjung wisatawan.
\end{abstract}

Kata Kunci - Digital Marketing; Minat Berkunjung; Pertumbuhan Ekonomi; Sektor Pariwisata; Store Atmosphere.

\section{PENDAHULUAN}

Pandemi Covid-19 telah membawa dunia modern dalam kepanikan yang dengan cepat mengubah tatanan sosial, ekonomi, politik, dan budaya masyarakat. Kawasan Asia Tenggara yang tingkat perekonomiannya menduduki posisi terbesar ketujuh di dunia dan terbesar ketiga di Asia [1], adanya pandemi COVID-19 memberikan dampak langsung yang signifikan terhadap perekonomian negara-negara di kawasan ini [2]. Oleh karena itu, harus adanya upaya pemerintah di negara-negara yang berada di Kawasan Asia Tenggara untuk menjaga stabilitas perekonomian di tengah krisis akibat pandemi COVID-19 termasuk negara Indonesia. Pemerintah melakukan beberapa strategi seperti melakukan belanja besar-besaran guna meredam kontraksi ekonomi akibat pandemi Covid-19, membentuk Komite Penanganan Covid-19 dan Pemulihan Ekonomi Nasional, memberi bantuan kredit berbunga rendah, dan menyiapkan berbagai program agar UMKM bergeliat kembali, menempatkan dana di perbankan guna memutar roda ekonomi dan pemerintah melakukan penjaminan kredit modal kerja untuk korporasi [3].

Salah satu upaya meningkatkan tatanan ekonomi nasional adalah pengembangan aspek pariwisata dan UKM (usaha kecil dan menengah) yang berperan dalam penyerapan tenaga kerja sejalan dengan penelitian yang dilakukan untuk mengkaji peran pariwisata dan UKM terhadap penyerapan tenaga kerja di Garut Selatan, Jawa Barat, Indonesia [4]. UKM sebagai spread effect dari pariwisata menjadikan road mad Jawa Barat Prioritas Pembangunan 2018-2023 adalah pengembangan destinasi dan infrastruktur Pariwisata[5], pembangunan kepariwisataan diarahkan pada peningkatan sektor pariwisata menjadi sektor andalan yang mampu menggalakan kegiatan ekonomi termasuk kegiatan sektor lain yang terkait. Hal ini dimaksudkan agar 
pengembangan dan pendayagunaan berbagai potensi kepariwisataan nasional dapat meningkatkan peluang kerja, pendapatan asli daerah dan penerimaan devisa negara yang akan mendorong pertumbuhan ekonomi.

Kabupaten Garut dengan segala potensi wisata secara geografis berdekatan dengan Kota Bandung sebagai ibukota provinsi Jawa Barat merupakan daerah penyangga dan hitterland bagi pengembangan wilayah Bandung Raya yang mempunyai kedudukan strategis dalam memasok kebutuhan warga Kota dan Kabupaten Bandung serta berperan di dalam mengendalikan keseimbangan lingkungan [6]. Potensi daya tarik wisata yang dimiliki kota Garut, antara lain berupa keanekaragaman hayati, keunikan dan keaslian budaya daerah, keindahan bentang alam dan peninggalan sejarah [7]. Dinas Pariwisata dan Kebudayaan (Disparbud) Kabupaten Garut mencatat, dalam rentang 2019 terdapat sekira 2,8 juta yang berkunjung ke Garut. Dari jumlah tersebut, baru sekira 5 persennya wisatawan asal mancanegara sedangkan target tahun 2020 sebesar 3,1 jt wisatawan [8].

Minat (purchase intention) adalah keadaan mental seseorang yang mencerminkan rencana untuk melakukan beberapa tindakan dalam jangka waktu tertentu. Purchases intention dalam hubungannya dengan kunjungan wisatawan dalam pembelian jasa pariwisata disebut sebagai behavior attention to visit dalam hubunganya antara kualitas pelayanan yang dirasakan, nilai layanan, dan kepuasan serta pengaruh relatifnya terhadap perilaku minat beli [9]. Adapun data kunjungan wisatawan kabupaten Garut terlihat pada tabel di bawah ini:

Tabel 1: Kunjungan Wisatawan Periode 2019- 2020

\begin{tabular}{|c|c|c|}
\hline No & Tempat Wisata & Jumlah kunjungan \\
\hline 1 & Situ Cangkuang & 12.054 \\
\hline 2 & Situ Bagendit & 11.923 \\
\hline 3 & Papandayan & 33.515 \\
\hline 4 & Cipanas & 18.417 \\
\hline 5 & Darajat & 15.507 \\
\hline 6 & Pantai Santolo & 64.330 \\
\hline 7 & Taman Satwa Cikembulan & 22.639 \\
\hline & Total & 177.368 \\
\hline
\end{tabular}

Sumber : Disparbud Garut : 2020

Tabel diatas menggambarkan kondisi yang belum merata dalam minat berkunjung wisatawan pada lokasilokasi tertentu dilihat masih rendahnya jumlah kunjungan seperti pada lokasi wisata Situ Bagendit dan Situ Cangkuang, hal ini memerlukan sebuah terobosan baru di dalam mengembangkan sektor pariwisata. Pada era industri 4.0 Teknologi informasi dan komunikasi (TIK) merupakan sarana yang membantu dalam kehidupan dalam berbagai bidang termasuk dalam dunia pariwisata. Peranan TIK dalam dunia pariwisata sebagai sarana dan prasarana dalam mempromosikan pariwisata secara elektronik dengan nama digital marketing antara lain dapat didukung oleh aplikasi website, online advertising, media sosial, web forum dan aplikasi mobile. Melalui penerapkan digital marketing tourism akan tumbuh secara profesional dan global [10].

Kabupaten Garut memiliki prioritas utama dalam pembangunan industri pariwisata dengan beraneka ragam objek wisata yang dikenal dengan gurilaps (gunung, rimba, laut, pantai dan situ), beraneka ragam kesenian tradisional dan kebudayaan, adat istiadat setempat yang dapat dikemas menjadi komoditi pariwisata yang dapat dijual baik secara lokal, nasional dan secara internasional. Potensi wisata yang dimiliki Kabupaten Garut hendaknya dikomunikasikan dengan baik kepada wisatawan potensial. Beragam media sosial digunakan seperti Facebook, Instagram, Twitter, ataupun Blog [11]. Dibawah ini adalah data pengguna akun- akun Pariwisata Kabupaten Garut: 
Tabel 2: Jumlah dan Prosentase Akun Pariwisata di Kabupaten Garut Tahun 2019

\begin{tabular}{clll}
\hline No & \multicolumn{1}{c}{ Katagori } & Jumlah & Prosentase \\
\hline 1 & Usia: & & \\
& 10-14 Tahun & 12 & 22.6 \\
& 15-19 Tahun & 20 & 37.7 \\
& 20-24 Tahun & 21 & 39.6 \\
\hline 2 & Jenis Kelamin: & & \\
& Laki-Laki & 14 & 26,4 \\
& Perempuan & 39 & 73,6 \\
\hline 3 & Tingkat Pendidikan: & & \\
& SMP/MTs/Sederajat & 12 & 22.6 \\
& SMA/SMK/MAN/Sederajat & 26 & 49.05 \\
& > Diploma & 15 & 28.3 \\
\hline 4 & Jenis Pekerjaan: & & \\
& Pelajar & 38 & 71.6 \\
& Mahasiswa & 15 & 28.3 \\
\hline 5 & Tingkat Pendapatan: & & 35.8 \\
& <500 rb & 19 & 43.4 \\
& 500 rb - 1 jt & 23 & 20.8 \\
\hline 1 jt - 2 jt & 11 & \\
\hline
\end{tabular}

Sumber: Data Olahan, 2019

Tabel. 2, menggambarkan pengguna akun pariwisata di Kabupaten Garut yang masih rendah yakni sekitar 22 persen dengan pilihan mayoritas adalah Instagram. Instagram menempati posisi teratas sebagai digital marketing yang paling banyak digunakan oleh wisatawan sebesar 58\%. Digital Marketing juga memberikan pengaruh yang sangat besar terhadap peningkatan kunjungan wisata di Danau Toba dengan presentasi sebesar $59,8 \%$. Hal ini dipengaruhi cukup tingginya tingkat penggunaan terhadap konten/situs digital marketing seputar Danau Toba dengan presentase sebesar 84\% [12].

Faktor lain yang perlu dipertimbangkan adalah store atmosphere dimana menjadikan daya tarik tersendiri pengunjung wisata untuk datang kembali, seperti view indah, kerapihan, kebersihan, fasilitas, aksesabilitas dan seterusnya sejalan dengan penelitian Heru Aulia Azman dan Yesi Elsandra [13], bahwa variabel jarak, fasilitas dan aksesibilitas memiliki pengaruh yang positif terhadap jumlah kunjungan wisatawan di Agrowisata Bukittinggi. Hasil observasi awal pada lokasi Situ Bagendit Kabupaten Garut masih terdapat kekurangankekurangan dalam hal penataan lingkungan wisata seperti jalan yang masih kesulitan untuk di lalui mobil terutama pada Situ Bagendit 2, tempat sampah yang belum memadai sehingga sampah banyak tercecer, WC umum yang tidak terpelihara dan sebagainya padahal proyek revitalisasi Situ Bagendit menganggarkan cukup besar dana untuk membuat restoran apung sebagai bidikan pemasukan sektor wisata untuk pertumbuhan ekonomi khsusunya Kabupaten Garut. Berangkat dari inilah penulis untuk melakukan penelitian ini. Tujuan penelitian untuk mengetahui peran digital marketing terhadap minat berkunjung wisatawan dalam meningkatkan pertumbuhan ekonomi kabupaten garut dan store atmosphere sebagai variabel moderating. 


\section{METODE PENELITIAN}

Penelitian mengenai peran digital marketing terhadap minat berkunjung wisatawan dalam meningkatkan pertumbuhan ekonomi kabupaten Garut dengan store atmosfer sebagi variable moderating merujuk pada tujuan penelitian dengan menggunakan metode studi kasus mensyaratkan sumber data yang multi sources [14]. Pengumpulan data dilakukan dengan melakukan wawancara mendalam dan sumber data sekunder.

Adapun model penelitian dapat digambarkan sebagai berikut:

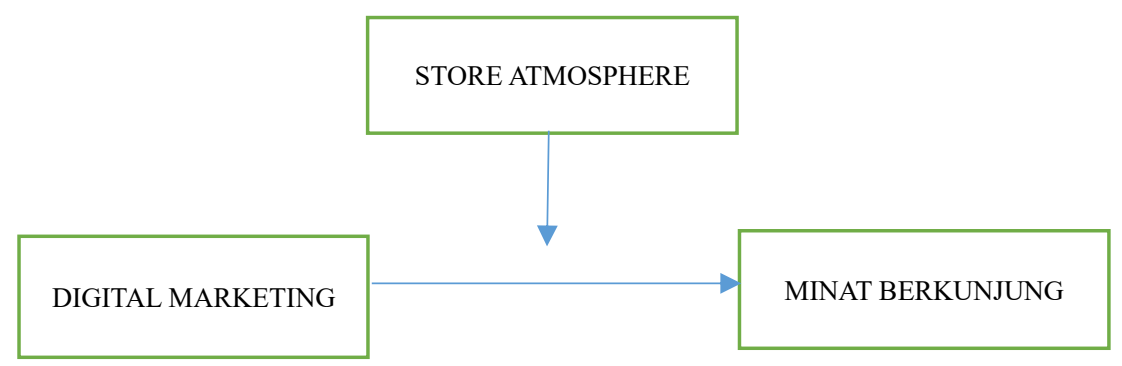

Gambar 1: Model Penelitian

\section{HASIL DAN DISKUSI}

Pertumbuhan ekonomi adalah suatu proses kenaikan output per kapita dalam jangka panjang. Dalam pengertian tersebut ada 3 hal yang perlu digaris bawahi yaitu proses, out put per kapita, dan jangka panjang. Pertumbuhan ekonomi tidaklah instan namun terdapat proses yang mengarah pada output perkapita. Pada saat ini pertumbuhan ekonomi di Kabupaten Garut saat ini ternyata mengalami minus sekitar 1,3 persen. Salah satu upaya memecahkan masalah tersebut dengan cara mengembangkan potensi wisata yang ada di Kabupaten Garut. Seluruh komponen mengembangkan pariwisata yang ada di Kabupaten Garut sejatinya dapat menumbuhkan kegiatan ekonomi daerah yang terpuruk tersebut. Pemkab Garut menganggarkan dana sekitar sepuluh miliar rupiah dari APBD Garut Tahun Anggaran 2022 untuk pengembangan pariwisata untuk menggerakkan sektor produktif untuk secara domino dapat memotori sektor produktuf lain termasuk UMKM yang menyerap banyak tenaga kerja. Dibawah ini adalah beberapa lokasi wisata di kabupaten Garut:

Tabel 3. Keistimewaan Lokasi Destinasi Wisata di Kabupaten Garut

\begin{tabular}{|c|c|c|c|}
\hline No & Nama Tempat Wisata & Keistimewaan & Lokasi \\
\hline 1 & Leuwi Jurig & $\begin{array}{l}\text { Memiliki magnet luar biasa bagi } \\
\text { wisatawan karena pemandangannya yang } \\
\text { mempesona. Dikenal dengan sebutan } \\
\text { grand canyon mini ala garut ini. Terletak di }\end{array}$ & $\begin{array}{l}\text { Kecamatan Bungbulang, } \\
\text { Kabupaten Garut. }\end{array}$ \\
\hline 2 & Situ Bagendit & $\begin{array}{l}\text { Danau dengan rakit bambu ataupun bebek } \\
\text { air, menikmati serunya suasana di arena } \\
\text { bermain hingga menjelajahi pasar } \\
\text { tradisional yang ada di sekitar danau. }\end{array}$ & $\begin{array}{l}\text { Kecamatan Banyuresmi, } \\
\text { Kabupaten Garut. }\end{array}$ \\
\hline 3 & $\begin{array}{l}\text { Candi Cangkuang dan } \\
\text { Kampung Pulo }\end{array}$ & $\begin{array}{l}\text { Letak candi ini berada di sebuah daratan di } \\
\text { tengah danau juga terdapat Kampung Pulo } \\
\text { yang merupakan pemukiman ada }\end{array}$ & $\begin{array}{l}\text { Desa Cangkuang, Kecamatan } \\
\text { Leles, Kabupaten Garut }\end{array}$ \\
\hline 4 & $\begin{array}{l}\text { Kawasan } \\
\text { Cipanas Garut }\end{array}$ & $\begin{array}{l}\text { Pemandian air panas yang bisa digunakan } \\
\text { untuk berendam. }\end{array}$ & $\begin{array}{l}\text { Letaknya yang tidak begitu } \\
\text { jauh dari pusat kota Garut }\end{array}$ \\
\hline 5 & $\begin{array}{l}\text { Kawasan } \\
\text { Darajat Garut }\end{array}$ & $\begin{array}{l}\text { Pemandangan lembah di bawahnya yang } \\
\text { mempesona. Terdapat banyak pilihan } \\
\text { kolam pemandian air panas yang bisa } \\
\text { digunakan untuk berendam dan bersantai. }\end{array}$ & $\begin{array}{l}\text { Terletak di sekitar } 25 \mathrm{~km} \text { dari } \\
\text { pusat kota Garut }\end{array}$ \\
\hline
\end{tabular}




\begin{tabular}{|c|c|c|c|}
\hline No & Nama Tempat Wisata & Keistimewaan & Lokasi \\
\hline 6 & Karacak Valley & $\begin{array}{l}\text { Air terjun dan fasilitas camping ground } \\
\text { bagi pengunjung yang ingin menikmati } \\
\text { suasana alam terbuka dengan berkemah. }\end{array}$ & $\begin{array}{l}\text { Desa Margawati, Kecamatan } \\
\text { Garut Kota, Kabupaten } \\
\text { Garut. }\end{array}$ \\
\hline 7 & Kawah Talaga Bodas & $\begin{array}{l}\text { Ada dua jenis tempat pemandian air panas } \\
\text { yang bisa dipilih pengunjung, yaitu kolam } \\
\text { air panas di kawah Talaga Bodas dengan } \\
\text { beberapa kolam kecil terbuka dan } \\
\text { Pancuran } 7 \text { Talaga Bodas. }\end{array}$ & $\begin{array}{l}\text { Kawah talaga bodas terletak } \\
\text { sekitar } 28 \mathrm{KM} \text { dari ibu kota } \\
\text { Garut }\end{array}$ \\
\hline 8 & Kebun Mawar Situhapa & $\begin{array}{l}\text { Hamparan kebun bunga aneka warna } \\
\text { menjadi pemandangan alam yang begitu } \\
\text { mempesona, sangat cocok untuk dijadikan } \\
\text { spot foto yang menarik }\end{array}$ & $\begin{array}{l}\text { Lokasi di Jalan Kamojang } \\
\text { Km 5, Samarang, Kabupaten } \\
\text { Garut. }\end{array}$ \\
\hline 9 & Kawah Kamojang & $\begin{array}{l}\text { Setidaknya ada } 23 \text { titik kawah yang berada } \\
\text { di lokasi ini, dimana dua diantaranya } \\
\text { berbentuk seperti danau uap. Konon uap } \\
\text { yang dihasilkan kawah ini sangat } \\
\text { berkhaisat untuk kesehatan kulit, } \\
\text { sementara aroma uapnya juga diyakini } \\
\text { mampu melancarkan peredaran darah dan } \\
\text { sistem pernafasan. }\end{array}$ & $\begin{array}{l}\text { Samarang, Kabupaten Garut, } \\
\text { Jawa Barat. }\end{array}$ \\
\hline 10 & $\begin{array}{l}\text { Kebun } \\
\text { Cikembulan }\end{array}$ & $\begin{array}{l}\text { Dengan suasana alamnya yang rindang dan } \\
\text { sejuk, pengunjung bisa berjalan-jalan } \\
\text { menikmati rindangnya pepohonan dengan } \\
\text { menyaksikan tingkah polah aneka jenis } \\
\text { satwa yang ada. }\end{array}$ & $\begin{array}{lr}\text { di Kampung Jati, Desa } \\
\text { Cikembulan, } & \text { Kecamatan } \\
\text { Kadungora, Kabupaten Garut }\end{array}$ \\
\hline 11 & $\begin{array}{l}\text { Darajat Pass } \text { Water } \\
\text { Park }\end{array}$ & $\begin{array}{l}\text { Ada banyak wahana permainan air yang } \\
\text { bisa dicoba dengan aliran air hangat yang } \\
\text { membuat tubuh merasa rileks dan nyaman. } \\
\text { Selain bermain air, pengunjung juga bisa } \\
\text { mencoba tantangan yang lebih seru dengan } \\
\text { kegiatan outbound dan flying fox. }\end{array}$ & $\begin{array}{l}\text { Desa Karyamekar, } \\
\text { Kecamatan Pasirwangi, } \\
\text { Kabupaten Garut, }\end{array}$ \\
\hline 12 & $\begin{array}{l}\text { Situ Kabuyutan } \\
\text { Read more } \\
\text { https://nyero.id/tempat- } \\
\text { wisata-di-garut/ }\end{array}$ & $\begin{array}{l}\text { Lokasi danaunya yang dikelilingi oleh } \\
\text { bebatuan cadas dan pohon pinus membuat } \\
\text { suasana alam terasa semakin damai dan } \\
\text { menyejukkan pandangan. }\end{array}$ & $\begin{array}{lr}\text { Desa } & \text { Pasirlayung, } \\
\text { Kecamatan } & \text { Pakanjeng, } \\
\text { Kecamatan Bungbulang, } \\
\text { Kabupaten Garut }\end{array}$ \\
\hline 13 & $\begin{array}{l}\text { Read more } \\
\text { https://nyero.id/tempat- } \\
\text { wisata-di-garut/ }\end{array}$ & $\begin{array}{l}\text { Dengan suhu air sekitar } 30 \text { derajat Celsius, } \\
\text { pengunjung bisa berendam dan menikmati } \\
\text { keindahan alam di sekitarnya yang } \\
\text { menyejukkan. Air panas dengan } \\
\text { kandungan sulfur berasal dari Kawah } \\
\text { Papandayan sehingga diyakini mampu } \\
\text { memberikan efek yang menyehatkan juga } \\
\text { terdapat camping ground. }\end{array}$ & $\begin{array}{l}\text { Desa Sirnajaya, Kecamatan } \\
\text { Cisurupan, Kabupaten Garut }\end{array}$ \\
\hline 14 & Pantai Santolo & $\begin{array}{l}\text { Pantai Santolo adalah pantai yang tidak } \\
\text { terlalu ramai, kumpulan batu besar dan laut } \\
\text { yang berwarna biru menjadi pemandangan } \\
\text { yang sangat mempesona. }\end{array}$ & $\begin{array}{l}\text { Lokasi di Kecamatan Cikelet, } \\
\text { Kabupaten Garut, Jawa } \\
\text { Barat, Indonesia }\end{array}$ \\
\hline
\end{tabular}

Sumber : Disparbud Garut, 2019

Tabel diatas menggambarkan beberapa destinasi wisata di Kabupaten Garut yang sangat layak untuk dikunjungi. Jumlah kunjungan tahun 2021 sebanyak 126.510 kunjungan dengan penggunaan promosi lewat 
digital seperti Instagram yang baru mencapai 22 persen [15]. Hal ini tentu masih membutuhkan peningkatan digital marketing dalam upaya promosi wisata di kabupaten Garut.

Penggunaan sarana promosi yang sejalan dengan kondisi pandemi saat ini diperlukan agar peningkatan jumlah wisatawan dapat dicapai dengan tingkat efisiensi yang tinggi. Teknologi, dalam hal ini media komunikasi memiliki peranan penting dalam menyukseskan kegiatan pemasaran pariwisata in the world of rapid technological evolution and economy of digitalization, consumers are continuously changing. Tourist are among the first [16]. Penggunaan media digital dalam kegiatan promosi pariwisata terus berkembang sejalan dengan meningkatnya pengguna media digital di Indonesia, 175,4 juta orang di Indonesia terakses ke internet dan 160 juta diantaranya merupakan pengguna media sosial yang aktif [17].

Penggunaan media digital dalam pemasaran yang dapat menjangkau para pengguna internet menjanjikan pasar yang lebih luas yang mana social media marketing salah satu penelitian juga membuktikan bahwa media sosial memiliki pengaruh positif dan signifikan terhadap kepercayaan konsumen pada produk yang dipasarkan atau merek yang digunakan [18]. Penggunaan beragam platform digital yaitu website, facebook dan Instagram untuk memasarkannya dinilai efektif karena mampu menyebarkan konten yang cukup memberikan gambaran tentang lokasi wisata dan memiliki kemasan konten yang menarik karena terdiri dari beragam format baik teks, foto maupun video. Semakin banyak orang yang berkunjung baik internasional, nasional dan lokal, merupakan salah satu bukti efektivitas komunikasi pemasaran yang diperoleh serta dampaknya pada masyarakat [19].

Akun instagram @galerigarut_merupakan salah satu akun populer yang mengangkat tema tentang pariwisata di Kabupaten Garut serta banyak mengunggah tempat menarik yang jarang diketahui masyarakat. Hal ini dapat dilihat dari jumlah followersnya yang mencapai 78,2 ribu pengikut dan jumlah postingannya sudah mencapai 3 ribu lebih, dapat membantu pemerintah untuk mempromosikan pariwisata yang ada di setiap daerah terutama di Kabupaten Garut [20].

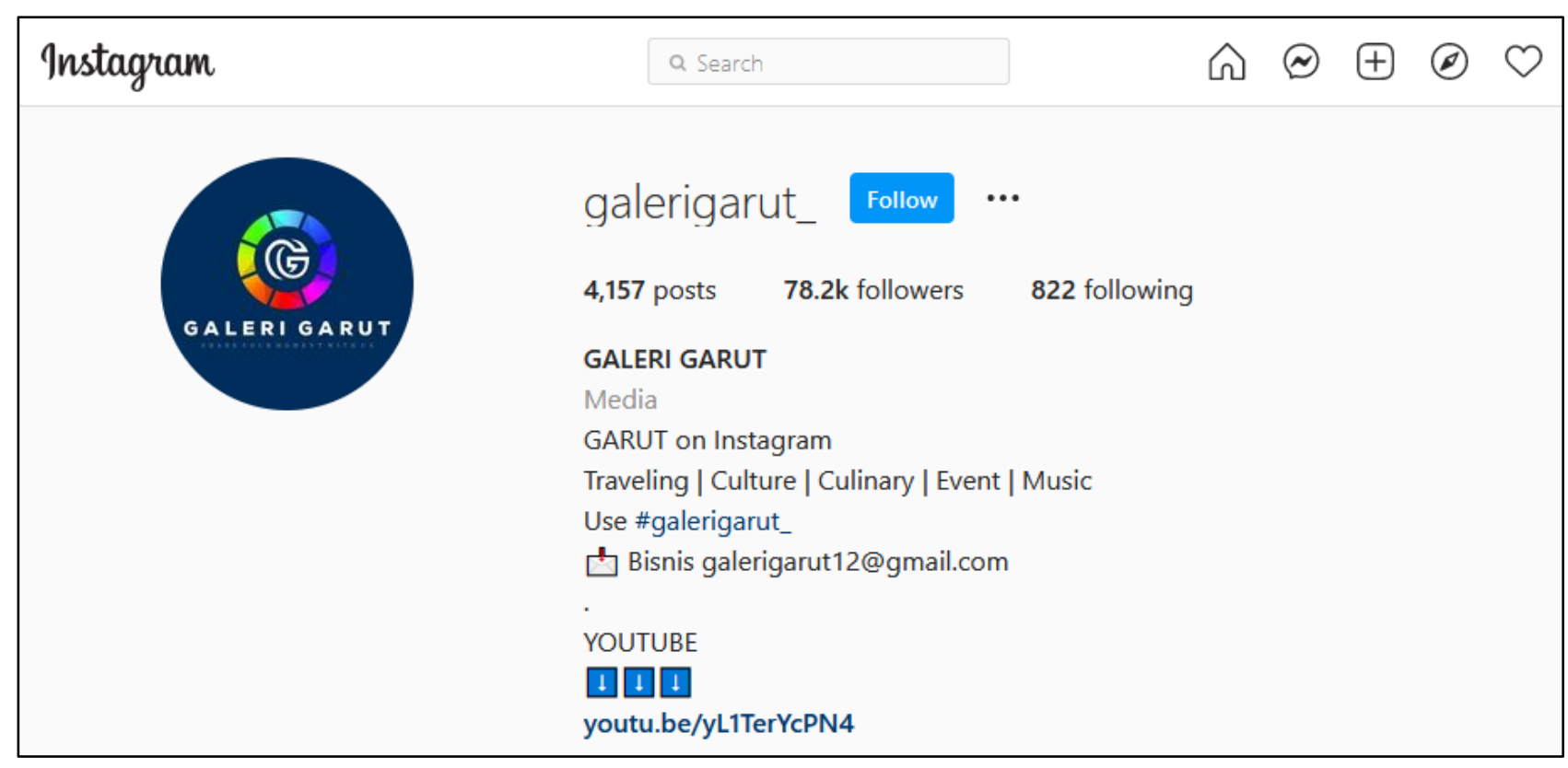

Gambar 2: Instagram Galeri Garut

Faktor lain yang menunjang minat berkunjung masyarakat pada destinasi wisata adalah store atmosphere sejalan dengan penelitian Fitriani dan Herry Nurdin [21], yang mana Store Atmosphere berpengaruh terhadap minat beli ulang konsumen seperti sarana-sarana: 

a. Musholla tempat ibadah yang baik dan terawat.
b. Toilet yang bersih dan nyaman.
c. Area Bermain Anak, seperti ayunan, prosotan, tempat petak umpet mini, dan sebagainya.
d. Area Out Bond yang akan memberikan kesan kepada pengunjung.
e. Aksesabilitas ke area desinasi wisata yang lancar dan aman [22].

Tabel 4: Kendala Lingkungan Pada Destinasi Wisata di Kabupaten Garut

\begin{tabular}{cll}
\hline No & Tempat wisata & \multicolumn{1}{c}{ Kendala Lingkungan } \\
\hline 1 & Situ Bagendit & $\begin{array}{l}\text { Di kawasan ini terdapat pencemaran sampah dan vandalisme berupa } \\
\text { coretan di bangunan dan pohon. Visabilitas di kawasan ini sedikit terhalang, } \\
\text { tingkat kebisingan yang sedang dan terdapat rambu iklan serta akses jalan } \\
\text { yang belum memadai }\end{array}$ \\
\hline 2 & Situ Cangkuang & $\begin{array}{l}\text { Selain kendala air pada musim kemarau juga tumbuhan teratai yang tidak } \\
\text { dirawat pada danau tersebut menjadi pemandangan yang kurang baik }\end{array}$ \\
\hline 3 & Papandayan & $\begin{array}{l}\text { Akses ke lokasi wisata masih rusak serta belum lengkapnya sarana yang } \\
\text { diperlukan untuk destinasi wisata }\end{array}$ \\
\hline 4 & Cipanas & $\begin{array}{l}\text { Terdapat beberapa lokasi yang masih kotor dan tidak terawatt } \\
\text { kebersihannya serta calo parker yang mrengganggu pengunjung }\end{array}$ \\
\hline 5 & Darajat & $\begin{array}{l}\text { Selain lokasi yang jauh dari perkotaan juga ancaman bahaya longsor yang } \\
\text { seringkali menjadi pertimbangan pengunjung untuk datang ke lokasi ini }\end{array}$ \\
\hline
\end{tabular}

Tabel diatas memperlihatkan masih terdapat beberapa kelemahan lingkungan yang menjadi kendala bagi minat berkunjung pada destinadi wisata di kabupaten Garut. Adapun peran digital yang mulai dari menentukan target pasar, melakukan promosi penjualan, bekerjasama dengan media khusus promosi, serta membangun image melalui foto dan video yang di unggah dalam Instagram [23], dapat meningkatkan hasrat pengunjung dalam memilih destinasi wisata, namun harus pula didukung oleh store atmosphere yang terpelihara dan terawat dengan baik, sejalan dengan penelitian Rennyta Yusiana, Putri Ayu Nuraisyah [24] dimana konsumen juga mengutamakan store atmosphere. Sebuah destinasi wisata sangatlah urgen untuk melakukan promosi yang efektif serta mengikuti perubahan zaman seperti penggunaan sistem teknologi namun faktor kenyamanan, kerapihan, kebersihan, prasarana dan sejenisnya harus diperhatikan pula oleh karena urgensi wisatawan pada hakekatnya untuk berlibur (refreshing) dari aktivitas keseharian dan kepenatan dalam dunia kerja. Saat ini, Pengembangan sektor jasa maupun UKM tidak akan terlepas dari sistem teknologi diantaranya adalah digital marketing sebagai perangkat yang dapat mendongkrak pemasaran [25].

\section{KESIMPULAN}

Penelitian ini menyimpulkan beberapa rekomendasi sebagai berikut:

1. Kabupaten Garut memiliki potensi yang besar di bidang pariwisata yang dapat meningkatkan pertumbuhan ekonomi dan kesejahteraan masyarakat.

2. Upaya mendorong laju sektor pariwisata salah satunya dengan digital marketing dengan tetap memperhatikan aspek store atmosphere.

3. Tujuan wisata adalah untuk berlibur (refreshing) dari aktivitas keseharian dan kepenatan dalam dunia kerja maka aspek yang menunjang hal tersebut harus menjadi perhatian utama sehingga minat berkunjung ke lokasi wisata diharapkan dapat meningkat.

\section{UCAPAN TERIMA KASIH}

Dalam penulisan jurnal ini, penulis mengucapkan terimakasih sebesar-besarnya kepada segenap redaktur Institut Teknologi Garut. Semoga senantiasa sukses, maju dan berkah. 


\section{DAFTAR PUSTAKA}

[1] WEF, "World Economic Forum Annual Report 2016," Am. J. Pharm. Educ., 2016.

[2] M. A. Fauzi and N. Paiman, "COVID-19 pandemic in Southeast Asia: intervention and mitigation efforts," Asian Education and Development Studies. 2021, doi: 10.1108/AEDS-04-2020-0064.

[3] "5 Upaya Pemerintah Kembalikan Pertumbuhan Perekonomian Nasional Halaman 2 - Kompas.com." https://nasional.kompas.com/read/2020/08/07/16224171/5-upaya-pemerintah-kembalikanpertumbuhan-perekonomian-nasional?page $=2($ accessed Dec. 03, 2021).

[4] H. S. Hanifah, D. A. Kurniawan, and R. Pasciana, "TOURISM POTENTIAL, PRODUCTIVITY OF SMALL AND MEDIUM ENTREPRISES (SMES) : IMPACT ON THE IMPLEMENTATION OF LABOR IN SOUTH GARUT, WEST JAVA, INDONESIA," Sustain. Collab. Business, Technol. Inf. Innov, vol. 0, no. 0, Jan. 2019, Accessed: Dec. 03, 2021. [Online]. Available: https://openlibrarypublications.telkomuniversity.ac.id/index.php/scbtii/article/view/8381.

[5] R. J. Kusumah, "Pengembangan Pariwisata di Jawa Barat - Penelusuran Google," 2020. http://bappeda.jabarprov.go.id/wp-content/uploads/2020/01/Pariwisata-Jabar_narasumber_Reboan07-01-19.pdf (accessed Dec. 03, 2021).

[6] “Pemerintah Kabupaten Garut.” https://www.garutkab.go.id/ (accessed Dec. 03, 2021).

[7] H. M. Desi Qoriah, Marti Dewi Ungkari, "Pengembangan Pariwisata Berkelanjutan Wisata Domba Adu Di Desa Rancabango Tarogong Kaler Garut," Tour. Manag. Perspect., 2019.

[8] "Kabupaten Garut-Dinas Pariwisata dan Kebudayaan Provinsi Jawa Barat." http://disparbud.jabarprov.go.id/wisata/disc-det.php?id=8\&lang=id (accessed Dec. 03, 2021).

[9] R. Basiya and H. Abdul Rozak, "Kualitas Dayatarik Wisata, Kepuasan Dan Niat Kunjungan Kembali Wisatawan Mancanegara Di Jawa Tengah," J. Ilm. Din. Kepariwisataan, 2012.

[10] I. G. A. K. Warmayana, "Pemanfaatan Digital Marketing dalam Promosi Pariwisata pada Era Industri 4.0," PARIWISATA BUDAYA J. Ilm. AGAMA DAN BUDAYA, 2018, doi: 10.25078/pba.v3i2.649.

[11] E. Trihayuningtyas, W. Wulandari, and Y. Adriani, "Media Sosial Sebagai Sarana Informasi Dan Promosi Social Media As a Mean of Tourism Information and," Tour. Sci. J., 2018.

[12] D. Yanti, "Pengaruh Digital Marketing Terhadap Peningkatan Kunjungan Wisata Di Danau Toba," Khasanah Ilmu - J. Pariwisata Dan Budaya, 2020.

[13] H. A. Azman and Y. Elsandra, "Analisis Faktor-Faktor yang Mempengaruhi Minat Kunjungan Berulang Wisatawan Milenial ke Bukittinggi," AMAR (Andalas Manag. Rev., 2020, doi: 10.25077/amar.4.1.117.2020.

[14] D. Mulyana, "Metode penelitian kualitatif: Paradigma baru ilmu komunikasi dan ilmu sosial lainnya," Bandung: Remaja Rosdakarya. 2008.

[15] "Jumlah Kunjungan Wisman pada September 2021 Alami Kenaikan Dibanding Bulan Sebelumnya Data - Tempo.co.” https://data.tempo.co/data/1252/jumlah-kunjungan-wisman-pada-september-2021alami-kenaikan-dibanding-bulan-sebelumnya (accessed Dec. 03, 2021).

[16] L. Gorlevskaya, "Building Effective Marketing Communications in Tourism," Stud. Commer. Bratisl., 2016, doi: 10.1515/stcb-2016-0025.

[17] Hootsuite, "Hootsuite (We Are Social) Indonesia Digital report 2020," Glob. Digit. Insights, 2020.

[18] A. R. Zulfikar and M. Mikhriani, "PENGARUH SOCIAL MEDIA MARKETING TERHADAP BRAND TRUST PADA FOLLOWERS INSTAGRAM DOMPET DHUAFA CABANG YOGYAKARTA," Al-Idarah J. Manaj. dan Adm. Islam, 2017, doi: 10.22373/al-idarah.v1i2.1663.

[19] Y. Hereyah and C. K. AW, "Pemanfaatan Media Vlogging Untuk Pengembangan Pemasaran Desa Wisata Kabupaten Lebak (Sawarnah Dan Bayah)," Pros. Konf. Nas. Pengabdi. Kpd. Masy. dan Corp. Soc. Responsib., 2020, doi: 10.37695/pkmcsr.v3i0.1018.

[20] P. Pundenswari, W. Andriyas, and A. Ramdhani, "ANALISIS SEMIOTIKA PADA AKUN INSTAGRAM@GALERIGARUT_DALAM PROMOSI PARIWISATA DI KABUPATEN GARUT," Collab. Gov. dalam Pengemb. Pariwisata di Indones., 2019.

[21] F. RIDWAN and H. Nurdin, "The Effect Of Store Atmosphere On Re-Visit Breaktime Interest In Bima City,” Econ. Depos. J., 2020, doi: 10.36090/e-dj.v2i1.724.

[22] "Faktor-Faktor Pendukung Kesehatan Pariwisata." https://www.sehatkerjaku.com/artikel/faktorfaktor-pendukung-kesehatan-pariwisata/ (accessed Dec. 04, 2021). 
[23] C. Widianti and W. A. Wiksana, "Digital Marketing dalam Promosi Kunjungan Wisata," Pros. Manaj. Komun., vol. 6, no. 2, pp. 318-323, Aug. 2020, doi: 10.29313/.V6I2.22776.

[24] P. A. Nuraisyah and R. Yusiana, "Peranan Store Atmosphere Dalam Meningkatkan Keputusan Pembelian," J. Ecodemica, 2017.

[25] H. M. Taiminen and H. Karjaluoto, "The usage of digital marketing channels in SMEs," J. Small Bus. Enterp. Dev., 2015, doi: 10.1108/JSBED-05-2013-0073. 